VOLUME 2 Ternary and Quaternary III-V Compounds

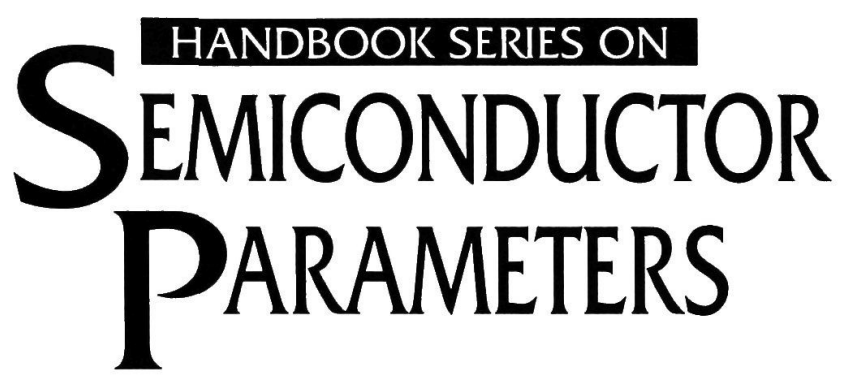




\section{HANDBOOK SERIES ON SEMICONDUCTOR PARAMETERS}

\section{edited by M. Levinshtein, S. Rumyantsev and M. Shur}

Vol. 1: Si, Ge, C (Diamond), GaAs, GaP, GaSb, InAs, InP, InSb

Vol. 2: Ternary and Quaternary $A_{3} B_{5}$ Semiconductors 
2 Ternary and Quaternary III-V Compounds

\section{HANDBOOK SERIES ON}
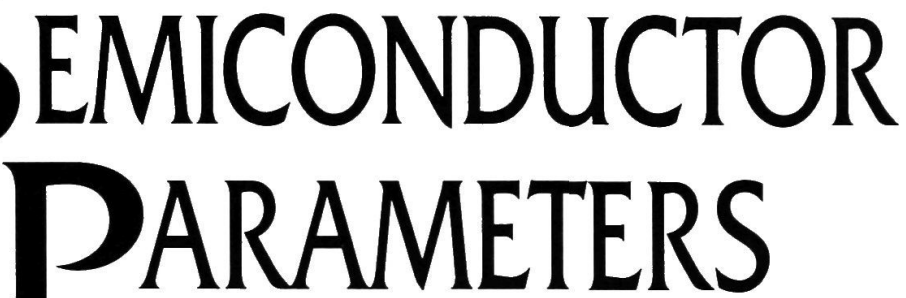

Editors

M LEVINSHTEIN S RUMYANTSEV

loffe Institute

M SHUR

Rensselaer Polytechnic Institute 


\section{Published by}

World Scientific Publishing Co. Pte. Ltd.

P O Box 128, Farrer Road, Singapore 912805

USA office: Suite 1B, 1060 Main Street, River Edge, NJ 07661

UK office: 57 Shelton Street, Covent Garden, London WC2H 9HE

\section{British Library Cataloguing-in-Publication Data}

A catalogue record for this book is available from the British Library.

\section{HANDBOOK SERIES ON SEMICONDUCTOR PARAMETERS VOLUME 2: Ternary and Quaternary $A_{3} B_{5}$ Semiconductors}

Copyright () 1999 by World Scientific Publishing Co. Pte. Ltd.

All rights reserved. This book, or parts thereof, may not be reproduced in any form or by any means, electronic or mechanical, including photocopying, recording or any information storage and retrieval system now known or to be invented, without written permission from the Publisher.

For photocopying of material in this volume, please pay a copying fee through the Copyright Clearance Center, Inc., 222 Rosewood Drive, Danvers, MA 01923, USA. In this case permission to photocopy is not required from the publisher.

ISBN 981-02-1420-0 (Set)

ISBN 981-02-2935-6

This book is printed on acid-free paper.

Printed in Singapore by Uto-Print 
To our friends in many countries 
This page is intentionally left blank 


\section{PREFACE}

This second volume of the Handbook Series on Semiconductor Parameters contains data on the most popular ternary and quaternary III-V compounds. To a certain extent, these compounds allow us to tailor material parameters optimizing these parameters for device applications and, at the same time, matching their lattice constants to available substrates. This is especially important for heterostructure devices, and the best semiconductor lasers and High Electron Mobility Transistors all use heterostructures based on ternary or quaternary compounds.

The technology and characterization of ternary and quaternary compounds are more complicated than for their binary counterparts. This is reflected in a variety and complexity of experimental data for the material parameters, often represented by interpolation formulas based on curve fits or on a linear regression. The parameters predicted by these formulas for the limiting values of the mole fractions ( $x=0$ or $x=1)$ may differ slightly from their values measured for the corresponding binary compounds. This should not be a cause for alarm. The situation is more serious when the differences in the values of the material parameters measured by different authors exceed the stated accuracy of the measurements. In such cases, we chose the values which we believed to be more reliable.

The data for each material in Volume II are organized in the same way, similar to how it was done in Volume I. This makes the search for information easier. We provided interpolation formulas in addition to graphs in order to make the information more quantitative. All in all, we tried to come up with a handbook, useful for every semiconductor researcher or engineer in their everyday work.

The discussion of the physical meaning of semiconductor parameters listed in this handbook may be found in "Introduction to Electronic Devices" by M. S. Shur (John Wiley and Sons, New York, 1995), which contains convenient tables summarizing the basic semiconductor equations and the definitions of basic semiconductor parameters. More detailed information is given in the two volume "Survey of Semiconductor Physics" by Karl Boer (van Nostrand, New York, 1990).

In some cases, the parameters, which one may need, are different from but related to the parameters given in this handbook. (This is especially true for parameters which are components of different tensors.) In this case, the book "Structure-Property Relations" by R. E. Newnhams (Springer-Verlag, New York, 1975) may be helpful. 
The additional information about the properties of III-V ternary and quaternary compounds may be found in the book by S. Adachi, "Properties of III-V Semiconductor Compounds", John Wiley and Sons, New York, 1992. The book by T. P. Pearsal (GaInAsP Alloy Semiconductors, John Wiley and Sons, New York, 1982) describes GaInAsP and elated materials. The properties of different III-V ternary and quaternary compounds are also summarized in the famous Landolt-Bornstein series, Numerical Data and Functional Relationship in Science and Technology, Springer, New York, 1982, and in the books of the Electronic Materials Information Service Datareviews Series from INSPEC (IEE Publishing). The volumes of the Datareviews Series relevant to the compounds discussed in this book are:

No. 2. Properties of Gallium Arsenide (2nd Edition, 1990)

No. 6. Properties of Indium Phosphide (1991)

No. 7. Properties of Aluminum Gallium Arsenide (1993)

No. 8. Properties of Lattice-Matched and Strained Indium Gallium Arsenide (1993)

We are grateful to our colleagues at A. F. Ioffe Institute who helped us to find information, made many excellent suggestions, and, in some cases, provided us with more accurate values of material parameters. Paraphrasing Bertrand Russell, we can say that "a parameter in science is not a fact, but an instance." Therefore, we will greatly appreciate any comments or suggestions, which can be e-mailed to M. E. Levinshtein and S. Rumyantsev (melev@nimis.ioffe.rssi.ru and sl@nimis.ioffe.rssi.ru) or to M. S. Shur (shurm@rpi.edu). 


\section{CONTENTS}

Preface vii

Chapter 1. Aluminium Gallium Arsenide $\left(\mathrm{Al}_{x} \mathrm{Ga}_{1-x} \mathrm{As}\right) \quad 1$

Yu. A. Goldberg

1.1. Basic Parameters at $300 \mathrm{~K}$

1.2. Band Structure and Carrier Concentration

1.2.1. Temperature Dependences 6

1.2.2. Dependences on Hydrostatic Pressure 8

1.2.3. Energy Gap Narrowing at High Doping Levels 9

1.2.4. Band Discontinuities at $\mathrm{Al}_{x} \mathrm{Ga}_{1-x} \mathrm{As} / \mathrm{GaAs}$ Heterointerface $\quad 10$

1.2.5. Effective Masses 11

1.2.6. Donors and Acceptors 12

$\begin{array}{ll}\text { 1.3. Electrical Properties } & 15\end{array}$

1.3.1. Mobility and Hall Effect 15

1.3.2. Two-Dimensional Electron and Hole Gas Mobility at $\mathrm{Al}_{x} \mathrm{Ga}_{1-x} \mathrm{As} / \mathrm{GaAs}$ Interface 19

1.3.3. Transport Properties in High Electric Field 21

1.3.4. Transport Properties of Electron and Hole Two-Dimensional Gas in High Electric Field 23

$\begin{array}{ll}\text { 1.3.5. Impact Ionization } & 24\end{array}$

1.3.6. Recombination Parameters 26

1.4. Optical Properties 28

1.5. Thermal Properties 31

1.6. Mechanical Properties, Elastic Constants, Lattice Vibrations, Other Properties 33

References 35

Chapter 2. Gallium Indium Phosphide $\left(\mathrm{Ga}_{x} \mathrm{In}_{1-x} \mathrm{P}\right)$

Yu. A. Goldberg

2.1. Basic Parameters at $300 \mathrm{~K} \quad 37$

2.2. Band Structure and Carrier Concentration $\quad 40$

2.2.1. Temperature Dependences 42 
2.2.2. Dependences on Hydrostatic Pressure

2.2.3. Energy Gap Narrowing at High Doping Levels 45

2.2.4. Band Discontinuities at Heterointerface $\quad 46$

2.2.5. Effective Masses $\quad 46$

2.2.6. Donors and Acceptors 47

2.3. Electrical Properties 48

2.3.1. Mobility and Hall Effect $\quad 48$

2.3.2. Two-Dimensional Electron Gas Mobility at $\mathrm{Ga}_{0.51} \mathrm{In}_{0.49} \mathrm{P} / \mathrm{GaAs}$ Interface $\quad 50$

2.3.3. Transport Properties in High Electric Fields 51

2.3.4. Impact Ionization $\quad 52$

2.3.5. Recombination Parameters 53

2.4. Optical Properties $\quad 54$

2.5. Thermal Properties 56

2.6. Mechanical Properties, Elastic Constants, Lattice Vibrations, Other Properties 57

$\begin{array}{ll}\text { References } & 59\end{array}$

Chapter 3. Gallium Indium Arsenide $\left(\mathrm{Al}_{x} \mathrm{In}_{1-x} \mathrm{As}\right)$

Yu. A. Goldberg and Natalya M. Schmidt

3.1. Basic Parameters at $300 \mathrm{~K}$

3.2. Band Structure and Carrier Concentration 65

3.2.1. Temperature Dependences 66

3.2.2. Dependences on Hydrostatic Pressure 68

3.2.3. Energy Gap Narrowing at High Doping Levels 69

3.2.4. Band Discontinuities at Heterointerfaces $\quad 69$

$\begin{array}{ll}\text { 3.2.5. Effective Masses } & 70\end{array}$

3.2.6. Donors and Acceptors 71

$\begin{array}{ll}\text { 3.3. Electrical Properties } & 72 \\ & \end{array}$

3.3.1. Mobility and Hall Effect $\quad 72$

3.3.2. Two-Dimensional Electron and Hole Gas Mobility in Heterostructures 75

3.3.3. Transport Properties in High Electric Field 77

$\begin{array}{ll}\text { 3.3.4. Impact Ionization } & 79\end{array}$

3.3.5. Recombination Parameters $\quad 80$

$\begin{array}{ll}\text { 3.4. Optical Properties } & 82\end{array}$

33.5. Thermal Properties

3.6. Mechanical Properties, Elastic Constants, Lattice Vibrations, Other Properties 85

$\begin{array}{ll}\text { References } & 87\end{array}$ 
Chapter 4. Gallium Indium Antimonide $\left(\mathrm{Ga}_{x} \mathrm{In}_{1-x} \mathrm{Sb}\right)$

Yu. A. Goldberg

4.1. Basic Parameters at $300 \mathrm{~K}$

4.2. Band Structure and Carrier Concentration 92

4.2.1. Temperature Dependences 93

4.2.2. Dependences on Hydrostatic Pressure 94

4.2.3. Effective Masses $\quad 95$

4.2.4. Donors and Acceptors 96

$\begin{array}{ll}\text { 4.3. Electrical Properties } & 97\end{array}$

4.3.1. Mobility and Hall Effect 97

4.3.2. Transport Properties in High Electric Field 100

$\begin{array}{ll}\text { 4.3.3. Recombination Parameters } & 101\end{array}$

$\begin{array}{lr}\text { 4.4. Optical Properties } & 102\end{array}$

4.5. Thermal Properties 105

4.6. Mechanical Properties, Elastic Constants, Lattice Vibrations, Other Properties 107

$\begin{array}{lr}\text { References } & 109\end{array}$

Chapter 5. Gallium Arsenide Antimonide $\left(\mathrm{GaAs}_{1-x} \mathrm{Sb}_{x}\right)$

A. Ya. 'Vul'

5.1. Basic Parameters at $300 \mathrm{~K}$

$\begin{array}{ll}\text { 5.2. Band Structure and Carrier Concentration } & 114\end{array}$

5.2.1. Temperature Dependences $\quad 115$

5.2.2. Dependences on Hydrostatic Pressure 116

$\begin{array}{ll}\text { 5.2.3. Effective Masses } & 117\end{array}$

5.2.4. Donors and Acceptors 117

$\begin{array}{ll}\text { 5.3. Electrical Properties } & 119\end{array}$

5.3.1. Mobility and Hall Effect $\quad 119$

$\begin{array}{ll}\text { 5.3.2. Impact Ionization } & 122\end{array}$

$\begin{array}{ll}\text { 5.4. Optical Properties } & 123\end{array}$

$\begin{array}{ll}\text { 5.5. Thermal Properties } & 126\end{array}$

5.6. Mechanical Properties, Elastic Constants, Lattice Vibrations, Other Properties 128

$\begin{array}{ll}\text { References } & 130\end{array}$

Chapter 6. Indium Arsenide-Antimonide (InAs $\left.\mathrm{s}_{1-x} \mathrm{Sb}_{x}\right) \quad 132$

ล M. S. Bresler

6.1. Basic Parameters at $300 \mathrm{~K}$

6.2. Band Structure and Carrier Concentration 
6.2.1. Temperature Dependences

6.2.2. Dependences on Hydrostatic Pressure 137

$\begin{array}{ll}\text { 6.2.3. Effective Masses } & 138\end{array}$

$\begin{array}{ll}\text { 6.2.4. Donors and Acceptors } & 138\end{array}$

$\begin{array}{ll}3 \text { 6.3. Electrical Properties } & 139\end{array}$

6.3.1. Mobility and Hall Effect 139

6.3.2. Impact Ionization $\quad 142$

6.3.3. Recombination Parameters 143

$\begin{array}{ll}\text { 6.4. Optical Properties } & 144\end{array}$

6.5. Thermal Properties 146

6.6. Mechanical Properties, Elastic Constants, Lattice Vibrations, Other Properties 148

$\begin{array}{ll}\text { References } & 151\end{array}$

Chapter 7. Gallium Indium Arsenide Phosphide $\left(\mathrm{Ga}_{x} \mathrm{In}_{1-x} \mathrm{As}_{y} \mathrm{P}_{1-y}\right)$

Yu. A. Goldberg and Natalya M. Shmidt

7.1. Basic Parameters at $300 \mathrm{~K}$

7.1.1. Basic Properties of $\mathrm{Ga}_{x} \mathrm{In}_{1-x} \mathrm{As}_{y} \mathrm{P}_{1-y}$ Compositions

Lattice-Matched to InP at $300 \mathrm{~K}(x \cong 0.47 y)$

154

7.2. Band Structure and Carrier Concentration 157

$\begin{array}{ll}\text { 7.2.1. Temperature Dependences } & 158\end{array}$

7.2.2. Dependences on Hydrostatic Pressure 160

7.2.3. Band Discontinuities at GaInAsP/InP Heterostructure 160

$\begin{array}{ll}\text { 7.2.4. Effective Masses } & 161\end{array}$

7.2.5. Donors and Acceptors 162

$\begin{array}{ll}\text { 7.3. Electrical Properties } & 164\end{array}$

7.3.1. Mobility and Hall Effect 164

7.3.2. Transport Properties in High Electric Field 167

$\begin{array}{ll}\text { 7.3.3. Impact Ionization } & 169\end{array}$

$\begin{array}{ll}\text { 7.3.4. Recombination Parameters } & 170\end{array}$

$\begin{array}{ll}\text { 7.4. Optical Properties } & 171\end{array}$

7.5. Thermal Properties 173

7.6. Mechanical Properties, Elastic Constants, Lattice Vibrations, Other Properties 175

$\begin{array}{ll}\text { References } & 178\end{array}$

Chapter 8. Gallium Indium Arsenide Antimonide $\left(\mathrm{Ga}_{x} \mathrm{In}_{1-x} \mathrm{As}_{y} \mathrm{Sb}_{1-y}\right)$ Maya P. Mikhailova

8.1. Basic Parameters at $300 \mathrm{~K}$ 
8.1.1. Basic Properties of $\mathrm{Ga}_{x} \mathrm{In}_{1-x} \mathrm{As}_{y} \mathrm{Sb}_{1-y}$ Compositions Lattice-Matched to $\mathrm{GaSb}$

8.1.2. Basic Properties of $\mathrm{Ga}_{x} \mathrm{In}_{1-x} \mathrm{As}_{y} \mathrm{Sb}_{1-y}$ Compositions Lattice-Matched to InAs

8.2. Band Structure and Carrier Concentration 186

8.2.1. Temperature Dependences 188

8.2.2. Band Discontinuities at GaInAsSb/GaSb and GaInAsSb/InAs Heterojunctions

8.2.3. Effective Masses 192

8.2.4. Donors and Acceptors 192

8.3. Electrical Properties 194

8.3.1. Mobility and Hall Effect 194

$\begin{array}{ll}\text { 8.3.2. Impact Ionization } & 196\end{array}$

$\begin{array}{ll}\text { 8.4. Optical Properties } & 197\end{array}$

$\begin{array}{ll}\text { 8.5. Thermal Properties } & 198\end{array}$

8.6. Mechanical Properties, Elastic Constants, Lattice Vibrations, Other Properties 201 References 204 